\title{
Resimli Hikaye ve Masal Kitaplarında Geçen Vicdan Gelişimine Yönelik İfadelerin İncelenmesi
}

\author{
DOI: $10.26466 /$ opus. 865378 \\ * \\ Fatma Balık* - Munise Duran** \\ *Milli Eğitim Müdürlüğü, Diclekent Anaokulu, Diyarbakır/Türkiye \\ E-Posta: fatmabalik1992@gmail.com ORCID: 0000-0002-8601-4619 \\ **Dr. Öğretim Üyesi, İnönü Üniversitesi, Eğitim Fakültesi, Malatya/Türkiye \\ E-Posta: munise.durdu@inonu.edu.tr ORCID: 0000-0001-8912-2669
}

Öz

$\mathrm{Bu}$ araştırma, okul öncesi döneme ait resimli hikâye ve masal kitaplarında vicdan gelişimini destekleyen ifadelerin neler olduğunu ve bu ifadelere ne oranda yer verildiğini tespit etmek amactyla yapılmıştır. Araştırmanın örneklemi, okul öncesi dönem resimli hikâye ve masal kitaplarından amaçlı örnekleme yöntemleri ile seçilmiş; daha çok kapağında karakter veya değerler eğitimi yazan, 2009-2020 yılları arasında yayınlanan 155 kitaptır. Araştırmada içerik analizi yönteminden yararlanılmıştır. Her bir kitap araştırmacılar tarafindan iki kez dikkatle okunmuş ve vicdan gelişimini desteklediği düşünülen ifadeler araştırmacilar tarafindan düzenlenen forma kaydedilmiştir. Bu ifadelere incelenmiş olan 155 kitaptan 91 kitapta rastlanmış; 64 kitapta ise hiç rastlanılmamıştır. Vicdan gelişimini desteklediği düşünülen 23 farklı ifade kaydedilmiştir. Bu ifadelerden kitaplarda en çok rastlanan üç ifade sırasıyla; "zor durumda-yardıma ihtiyacı olan kişilere yardım etmek", "hatasını anlamak", "başkalarına üzülmek-acımak-merhamet etmek" şeklindedir. Bu ifadelere rastlanan sayfa sayısinın incelenen tüm sayfa sayısina oranı \%11, 55 olarak bulunmuştur. Bu oran ve her bir ifadenin yer aldığı kitap sayısı düşük bulunmuştur. Çocuk eğitiminde yeri yadsınamayacak çocuk kitaplarında vicdan gelişimini destekleyen bu ifadelere daha çok yer verilmesi çocuğun bu ifadeleri içselleştirmesine ve kendi vicdan sistemini genişletip derinleştirmesine katkı sunacaktır.

Anahtar Kelimeler: Okul öncesi dönem, vicdan, vicdan gelişimi, çocuk kitapları 
ISSN:2528-9527

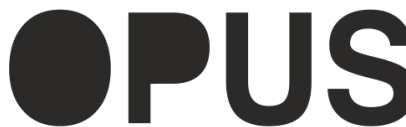

Uluslararası Toplum Araştırmaları Dergisi International Journal of Society Researches
E-ISSN : 2528-9535

YIl Year: 11

Cilt Volume: 17

Sayı Issue :37

Mayıs May 2021

Makalenin Geliş Tarihi Received Date: 20/01/2021

Makalenin Kabul Tarihi Accepted Date: 25/05/2021

\title{
Examination of Expressions Regarding Development of Conscience in Illustrated Story and Tale Books
}

$*$

\begin{abstract}
This research was carried out in order to determine the expressions that support the development of conscience in the picture story and tale books of the pre-school period and to what extent these expressions are included. The sample of the research was selected from preschool picture story and tale books, published in 2009-2020, with a prefix: 155 books with character or values education on the cover. Content analysis method was used in the research. Each book was carefully read twice by the researcher and the expressions thought to support the development of conscience were recorded in the form prepared by the researcher. The statement shave been found in 91 books: they have never been found in 64 books. 23 different expressions that were thought to support the development of conscience were recorded. Among these expressions the most common three expression in books is; "helping people in a difficult situation- helping people in need of help", "understanding the mistake", "pitying others-pitycompassion". The rate of the number of pages encountered with these expressions to the total number of pages examined was found to be \% 11,55. This rate and the number of books with each statement were found to be quite low. Including these expressions that support the development of conscience in children's book, which cannot be denied in children's education, will contribute to the child's internalization of these expressions and to expand and deepen his own conscience system.
\end{abstract}

Keywords: Conscience, development of conscience, children's books 


\section{Giriş}

Çocuğun kendisini bir birey olarak diğerlerinden farklı olarak algılamaya başladığı okul öncesi dönem sosyalleşme, toplumsallaşma ve bu bağlamda ahlak gelişimi açısından son derece önemlidir. Ahlak gelişimi, kişilik gelişiminin önemli bir parçasıdır ve çocukların içinde bulundukları toplumsal hayata uyum sağlayabilmelerinde gerekli kuralları öğrenmelerini ve benimsemelerini barındırmaktadır (Aydın, 2014; Tuzcuoğlu, 2014).

Ahlak gelişimi, bebeğin dünyaya gelmesiyle birlikte çevre ile etkileşim sonucu başlar ve özellikle iki yaşından itibaren çevreyle etkileşim arttıkça benimsenen toplumsal ilkeler de artarak ilerler (Özgün, 2012). Ahlak gelişimiyle ilgilenen araştırmacılara göre, kişilerin ahlaki değerleri zamanla kişiler fiziksel, zihinsel ve bilişsel açıdan ilerledikçe gelişmektedir. Ve bu gelişim süreci içerisinde ahlak gelişimi de diğer alanlar gibi gelişim göstermektedir (Torun, Özşahin ve Sütçügil, 2009). Çocuklar gelişim alanlarında ilerledikçe ahlaki açıdan düşüncelerini hızlandırarak arttırma yoluna giderler (Berk, 2013 b, s.567).

Çocuk gelişimi uzmanları ahlaki gelişim ile çocukların toplumsal hayata uyum sağlayabilmeleri için gerekli kuralları fark edip anlamalarını anlatmak istemişlerdir (Özeri, 2004). Ahlak gelişiminde en çok üzerinde durulması gereken konulardan biri; çocuğun küçük yaşlardan itibaren ahlaki kurallara inanmasını, bu kurallara ılımlı yaklaşım tarzı geliştirmesini ve bu kuralları davranışa dönüştürmesini gerçekleştirmedir (MEB, 2013, s.3).

Çocuk içinde yaşadığı toplumun inanç, değer ve ahlakını benimser ve tüm yaşamını bunlara uygun olarak devam ettirir. Bu durum bize çocuğun yaşamının ilk yıllarından itibaren toplumun değer yargılarına uygun bir eğitim programının gerekliliğini hatırlatır. Bu eğitim programlarının en çok tartışılan konularından biri de iyi bir insanın nasıl yetiştirileceğidir. İşte bu sorun ahlakın alanına girmektedir ve ahlak, eğitimin önemli bir konusu olmaktadır (Oruç, 2010).

Ahlak eğitiminin merkezinde vicdan eğitimi yer alır. Çünkü çocuğun ahlaklı olabilmesi güçlü bir vicdan barındırmasına bağlıdır (Yavuz, 1994). Vicdan iyi şeyler yaptığında kişiyi mutlu eden; kötü şeyler yaptığında kişinin mutsuz olmasına neden olan bir duygudur. Kişiyi doğru olana yönlendirip yanlışlardan uzaklaştırır. Fakat kişi yalnızca vicdanıyla doğruyu bu- 
lamaz. Vicdan kesinlikle iyi yönde eğitilmeli ve yönlendirilmelidir (Kahveci, 2012).

Vicdanlı kişi içerisinde kendisini denetleyen ve yönlendiren bir sistem barındırır. Vicdanlı kişiler taşıdıkları ahlaki kural ve değerlerin tüm yer ve zamanlarda geçerli olduğunu düşünürler. Ahlaki eğitim yalnızca çocuğa ahlaki açıdan bilgi verip çocuğun ahlaki kararlar almasını hedeflemez. Bunların yanında çocuğun ahlaki davranışı seçebilmesine yardımcı olan iç ve dış güçlerin dengelenmesini ve ahlaki nitelikleri içselleştirmiş, düzenli çalışan uyanık ve kuvvetli bir vicdan barındıran kişi olmasını amaçlar (Yavuz, 1994).

Çocuğun yaşamının ilk altı yılı kişilik gelişiminde oldukça kritiktir. Çünkü çocuk altı yaşına geldiğinde kişiliğin ana hatları belirlenmiş olacaktır. Bu hatlar çocuğun geleceğini her anlamda etkileyecek ve belirleyecektir. Vicdan gelişimi yaşamın geri kalan kısımlarında devam etse de yaşamın ilk yıllarındaki kısmı diğer dönemlere de etki etmektedir (Dodson, 1999). Küçük bir çocuk verdiği sözü tuttuğunda bunun ahlaki veya doğru bir davranış olduğunu algılayamayabilir. Fakat vicdan gelişim düzeyi arttıkça sözünü tutma davranışı ileriki dönemde çocukta sorumluluk ve görev bilincinin temelini oluşturmuş olacaktır (Rousseau, 2002).

Çocuklar için hazırlanan eserler öncelikle edebiyat ürünü olsalar da ahlak eğitimine de hizmet ederler. Bu eserler direkt olarak çocuğu eğitmek üzere yazılmasalar da çocukta iyi izlenim ve etkiler oluşturmayı hedefler. Çocukları erdemli olabilmeleri için mücadeleye teşvik eder, doğru kararlar almada onlara yardımcı olur, çocukların değer sistemi geliştirmelerini destekler, karşlaşabilecekleri olay ve durumlar karşısında olumlu tutum ve davranış ortaya koymalarını sağlar (Bohlin, 2005; Gibbs ve Earley, 1994; Karatay, 2007).

Okul öncesi dönem hikaye kitapların konu alan çalışmalar incelendiğinde vicdan gelişimini konu edinen araştırmaların sayısının yok denecek kadar az olduğu görülmektedir. Grinder 1964'te orta çocukluk döneminde vicdanın davranışsal ve bilişsel boyutlarını incelemiştir. Göllner, Damian, Rose, Spengler, Trautwein, Nagengas, Roberts (2017) tarafından ev ödevleri ve vicdan arasındaki ilişki incelenmiştir. Çocukuk döneminde vicdani gelişimi ele alan çalışmalar ile birlikte ayrıca, vicdani boyutta bazı ölçekler geliştirilmiştir (Aksan and Kochanska, 2005; Kochanska and Murray, 2000; Marjanovic, Struthers, Cribbie and Greenglass, 2014). Ahlak gelişiminin önemli 
bir parçası olan vicdan gelişiminin okul öncesi dönemde üzerinde durulması gereken bir konu olduğuna dikkat çekmek için böyle bir araştırmaya ihtiyaç duyulmuştur. Araştırmanın bu alanda çalışmak isteyen araştırmacılara, yazarlara, eğitimcilere, ebeveynlere ve okul öncesi dönem çocuklarına katkı sağlayacağı düşünülmektedir. Bu doğrultuda bu araştırmada 2009-2020 yılları arasında yayımlanan okul öncesi dönem resimli hikâye ve masal kitaplarının vicdan gelişimini destekleyen unsurlar yönünden incelenmesi amaçlanmıştır. Bu unsurlar ele alınırken; vicdanın davranış üzerindeki biçimlendirici, yönlendirici, engelleyici ve sorgulatıcı etkisi göz önünde bulundurulmuştur.

\section{Yöntem}

$\mathrm{Bu}$ bölümde araştırmanın modelinden, veri toplama aracından, verilerin toplanması ve analizi sürecinden bahsedilmiştir.

\section{Araştırmanın Modeli}

2009-2020 yılları arasında yayımlanmış okul öncesi dönem resimli hikâye ve masal kitaplarındaki vicdan gelişimini destekleyen öğeleri incelemeyi hedefleyen bu araştırma nitel araştırma yöntemlerinden içerik analizi modelinde bir çalışmadır. Nitel araştırma, araştırdığı problem durumuna ilişkin sorgulayıcl, yorumlayı ya yönelik bir yöntemdir (Guba ve Lincoln, 1994; Klenke, 2016). Bir problemin çözümüne ilişkin veri toplama yöntemlerinden gözlem, görüşme ve doküman analizi gibi teknikleri kullanan nitel araştırma, probleme ilişkin doğal olguların gerçekçi bir şekilde ele alınmasına yönelik öznelyorumlayıcı bir süreci izlemektedir (Baltacı, 2019; Seale, 1999).

\section{Araştırmanın Evren ve Örneklemi}

Araştırmanın evrenini okul öncesi döneme hitap eden resimli masal ve hikâye kitapları oluşturmaktadır. Örneklemini ise 2009-2020 yılında yayımlanmış, okul öncesi dönem resimli hikâye ve masal kitaplarından amaçlı örnekleme yöntemleri ile belirlenmiş kapağında daha çok karakter veya değerler eğitimi yazan 155 kitap oluşturmaktadır. Amaçlı örnekleme; araştırmanın amacına uygun, bilgi bakımından zengin durumların tercih edilerek derinlemesine araştırma imkanı sunar (Büyüköztürk, Çakmak, Akgün, 
Karadeniz ve Demirel, 2016). Örneklemde yer alan kitaplar Diyarbakır il merkezinde yer alan anaokullarının kitaplıklarından temin edilmiştir. Çalışmaya dahil edilen kitapların özellikleri tablo 1'de verilmiştir.

Tablo 1. Kitapların bazı değişkenlere göre dă̆ılımı

\begin{tabular}{|c|c|c|}
\hline Sayfa Sayısı & F & $\%$ \\
\hline $10-20$ & 115 & 74,19 \\
\hline $20-30$ & 2 & 1,29 \\
\hline $30-40$ & 38 & 24,52 \\
\hline Karakter & $\mathbf{F}$ & $\%$ \\
\hline İnsan & 17 & 10,97 \\
\hline Hayvan & 131 & 84,52 \\
\hline Diğer & 7 & 4,52 \\
\hline Yayınevi & $\mathbf{F}$ & $\%$ \\
\hline Gendaş & 24 & 15,48 \\
\hline Yumurcak & 10 & 6,45 \\
\hline Coşku & 10 & 6,45 \\
\hline Nar Çocuk & 20 & 12,90 \\
\hline Timaş & 60 & 38,71 \\
\hline Tanışır & 10 & 6,45 \\
\hline MEB Kültür & 14 & 9,03 \\
\hline Afs & 7 & 4,52 \\
\hline Basım Yilı & $\mathbf{F}$ & $\%$ \\
\hline 2009 & 12 & 7,74 \\
\hline 2010 & 8 & 5,16 \\
\hline 2011 & 11 & 7,10 \\
\hline 2012 & 1 & 0,65 \\
\hline 2013 & 8 & 5,16 \\
\hline 2014 & 79 & 50,97 \\
\hline 2015 & 7 & 4,52 \\
\hline 2017 & 15 & 9,68 \\
\hline 2020 & 14 & 9,03 \\
\hline Yazım Dili & $\mathbf{F}$ & $\%$ \\
\hline Yerli & 101 & 65,16 \\
\hline Çeviri & 54 & 34,84 \\
\hline Yazar Sayısı & $\mathbf{F}$ & $\%$ \\
\hline Tek Yazarlı & 132 & 85,17 \\
\hline İki Yazarlı & 9 & 5,80 \\
\hline Komisyon & 14 & 9,03 \\
\hline Yazar Cinsiyet & $\mathbf{F}$ & $\%$ \\
\hline Kadın & 15 & 65,21 \\
\hline Erkek & 7 & 30,43 \\
\hline Yazar Uzmanlık Alan & $\mathbf{F}$ & $\%$ \\
\hline Okul öncesi / Çocuk gelişimi & 6 & 26,08 \\
\hline Sinff öğretmenliği & 1 & 4,34 \\
\hline Dil bilim / Edebiyat & 15 & 65,21 \\
\hline MEB / ÖYGM & 1 & 4,34 \\
\hline
\end{tabular}


Tablo 1'e göre; araştırmaya dahil edilen okul öncesi döneme ait 155 resimli hikaye ve masal kitabının 115 tanesinin (\% 74,19) sayfa sayısının 10-20 aralığında; 2 tanesinin $(\%$ 1,29) sayfa sayısının 20-30 aralığında; 38 tanesinin (\% 24,52) sayfa sayısının 30-40 aralığında olduğu görülmektedir. Kitapların sayfa sayıları yazılırken son sayfaya verilen sayı baz alınmıştır.

131 tanesinin $(\%$ 84,52) karakterlerinin hayvanlardan oluştuğu, 17 tanesinin $(\% 10,97)$ karakterlerinin insanlardan oluştuğu, 7 tanesinin $(\% 4,52)$ karakterlerinin insan veya hayvan dışında (bitki, bulut, nesne) olduğu görülmektedir.

24 tanesinin (\% 15,48) Gendaş yayınlarına ; 10 tanesinin (\% 6,45) Yumurcak yayınlarına ; 10 tanesinin (\% 6,45) Coşku yayınlarına; 20 tanesinin (\% 12,90) Nar Çocuk yayınlarına; 60 tanesinin (\% 38,71) Timaş yayınlarına; 10 tanesinin (\% 6,45) Tanışır yayınlarına; 14 tanesinin (\% 9,03) MEB Kültür yayınlarına; 7 tanesinin $(\% 4,52)$ Afs yayınlarına ait olduğu görülmektedir.

12 tanesinin $(\%$ 7,74) 2009 yılında basıldığı; 8 tanesinin (\% 5,16) 2010 yılında basıldığı, 11 tanesinin $(\%$ 7,10) 2011 yılında basıldığı; 1 tanesinin (\% 0,65) 2012 yılında basıldığı; 8 tanesinin (\% 5,16) 2013 yılında basıldığı, 79 tanesinin (\% 50,97) 2014 yılında basıldığı; 7 tanesinin (\% 4,52) 2015 yılında basıldığ1; 15 tanesinin (\% 9,68) 2017 yılında basıldığ1; 14 tanesinin $(\% 9,03)$ 2020 yılında basıldığı görülmektedir.

101 tanesinin $(\%$ 65,16) yerli olduğu; 54 tanesinin $(\%$ 34,84) çeviri olduğu görülmektedir. 132 tanesinin (\% 85,17) tek yazarlı, 9 tanesinin $(\%$ 5,80) iki yazarlı, 14 tanesinin $(\% 9,03)$ ise komisyon çalışması ürünü olduğu görülmektedir.

23 farklı yazarın 15 tanesinin (\% 65,21) kadın, 7 tanesinin (\% 30,43) erkek, 1 tanesinin ise komisyon olduğu görülmektedir.

23 farklı yazarın 6 tanesinin $(\% 26,08)$ "okul öncesi / çocuk gelişimi" alan uzmanı, 1 tanesinin (\% 4,34) "sinıf öğretmenliği" alan uzmanı, 15 tanesinin (\% 65,21) "dil bilim/edebiyat" alan uzman, 1 tanesinin ise Milli Eğitim Bakanlığı Öğretmen Yetiştirme ve Geliştirme Genel Müdürlüğü olduğu görülmektedir.

\section{Verilerin Toplanmast}

$\mathrm{Bu}$ araştırma için araştırmacılar tarafından 3 maddelik analiz formu hazırlanmıştır. Bu formda, kitaplarda vicdan gelişimini destekleyen ifadelerin 
olup olmadığı, vicdan gelişimini destekleyen ifade varsa kitabın kaç sayfasında bunlara yer verildiği, bu ifadelerin neler olduğu ve ifadelerin geçtiği cümleler bölümlerine yer verilmiştir. Bu araştırmada kullanılan tüm kitaplar araştırmacılar tarafindan tek tek ve dikkatle okunmuş analiz formundaki ilgili yerlere bilgiler yazılmış ve gerekli kodlamalar yapılmıştır.

\section{Verilerin Analizi}

$\mathrm{Bu}$ araştırmada verilerin analiz edilmesinde içerik analizinden faydalanılmıştır. İçerik analizinde yazılı ya da resimli dökümanların detaylı bir şekilde incelenip analiz edilmesi söz konusudur (Ary, Razevieh ve Sorensen, 2006; Frankel ve Wallen, 2000; Patton, 2002). İçerik analizi ile elde edilen verilerin sayısal olarak ifade edilmesi sağlanmıştır. Nitel veriler bulguların yorumlanmasının kolaylaştııılması amacıyla nicel ifadelerle desteklenmiştir. İçerik analizinde esas olan verilerin belirli kategoriler ve amaçlar doğrultusunda ortak yönlerle birleştirilip anlaşılır hale getirilip değerlendirilmesidir (Büyüköztürk vd., 2016). Örnekleme dahil olan 155 çalışmanın analizinde 3 soru kullanılmıştır. Bu sorulardan her biri aynı zamanda içerik analizi için bir tema olarak kullanılmıştır. Araştırmada geçerliği sağlama yollarından biri de kapsam geçerliliğidir. Soruların amaca ne derece hizmet ettiği kapsam geçerliliği ile ilgilidir. Araştırmacılar kapsam geçerliliğini artırmak için hazırladığı soruları alandaki uzman akademisyenlere göstermiş ve onlardan bu soruların amaca uygun olup olmadığın belirlemeleri, ekleyecekleri başka soru varsa belirtmeleri istenmiştir. Onlardan gelen geri dönütlerle son hali verilen araştırma soruları şu şekildedir:

1. Kitapların vicdan gelişimine yönelik ifadeleri içermesine göre dağılımı nasıldır?

2. Kitapların içerdiği vicdan gelişimine yönelik kelimelerin dağılımı nasıldir?

3. Vicdan gelişimini desteklediği düşünülen ifadelerin yer aldığı sayfa sayısının dağılımı nasıldır?

155 çalışmanın analizinde 3 tema için alt temalar belirlenmiş ve kodlamalar yapılmıştır. Kodlamadaki iç tutarlılığı (güvenirliği) sağlamak amaciyla veriler araştırmacılar tarafından bağımsız olarak iki farklı zamanda olmak üzere iki kez kodlanmıştır. İkinci kodlama, birinci kodlamadan iki hafta sonra gerçekleştirilmiştir. Ayrıca kodlamalar üç farklı okul öncesi öğretme- 
nine daha okutulmuş ve onlardan oluşturulan temalar ve alt temalar doğrultusunda kodlama yapmaları istenmiştir. Daha sonra, kodlamalar birbiriyle karşılaştırılmış ve güvenirlik Miles ve Huberman (1994)'ın formülü (Güvenirlik = görüş birliği / görüş birliği + görüş ayrılığ X 100) kullanılarak hesaplanmıştır. Bu araştırmaya özgü olarak gerçekleştirilen güvenirlik bu kodlamalar arasındaki uyum \% 100 olarak hesaplanmıştır.

Kodlanan verilerin çözümlenmesi için SPSS paket programı kullanılmıştır. Bu amaçla öncelikle bütün temalar ve alt temalar SPSS paket programına aktarılmıştır. Daha sonra, ilgili temanın/alt temanın çalışmalarda mevcut olup olmadığına ("var" veya "yok" şeklinde) bakılmış ve bu temaların kaç kez tekrarlandığı frekans (f) ve yüzde (\%) olarak hesaplanmış, tablolaştırılarak verilmiştir.

\section{Bulgular}

2009-2020 yılları arasında yayımlanmış okul öncesi döneme ait 155 resimli masal ve hikâye kitabının analizi araştırma sorularına uygun olarak yapılmıştır. Elde edilen bulgular araştırma soruları doğrultusunda aşağıda yer almaktadır.

\section{Kitaplarnn Vicdan Gelişimini Destekleyen Ífadeleri İçerme Durumuna Göre Dağılımı}

Kitapların vicdan gelişimini destekleyen ifadeleri içerme durumuna göre dağılımları Tablo 2'da gösterilmiştir.

Tablo 2. Kitaplarnn Vicdan Gelişimini Destekleyen İfadeleri İçerme Durumuna Göre Dağılımı

\begin{tabular}{lll}
\hline Vicdani Bulgular & F & \% \\
\hline Var & 91 & 58,71 \\
\hline Yok & 64 & 41,29 \\
\hline
\end{tabular}

Tablo 2 incelendiğinde; araştırmaya dahil edilen okul öncesi döneme ait 155 resimli hikaye ve masal kitabının 91 tanesinde (\% 58,71) vicdan gelişimini destekleyen ifadelere rastlandığı; 64 tanesinde (\% 41,29) vicdan gelişimini destekleyen ifadelerin varlığına rastlanmadığı görülmektedir. 


\section{Kitaplarda Geçen Vicdan Gelişimini Desteklediği Düşünülen İfadeler}

Vicdan gelişimini desteklediği düşünülen ifadelerin neler olduğu, kaç farklı kitapta bu ifadelere yer verildiği ve bu ifadelerin yer aldığı kitap sayılarının tüm kitap sayısına oranına tablo 3'te yer verilmiştir.

Tablo 3. Vicdan Gelişimini Desteklediği Düşünülen Ifadelerin Rastlandıklan Kitap Sayısina Göre Oranları

\begin{tabular}{lll}
\hline İfade & $\mathbf{f}$ & $\mathbf{\%}$ \\
\hline Yaptı̆̆ından utanmak & 12 & 7,74 \\
\hline Özür dilemek, af dilemek & 21 & 13,54 \\
\hline Zor durumda olan-yardıma ihtiyacı olan kişilere yardım etmek & 35 & 22,58 \\
\hline Haksızlık yapmak, haksızlı̆̆a uğramak & 3 & 1,93 \\
\hline Hatasını anlamak & 33 & 21,29 \\
\hline Adil olmak & 5 & 3,22 \\
\hline Başkaları için üzülmek, acımak, merhamet & 23 & 14,83 \\
\hline Başkalarının yaşadıklarını anlama, empati & 11 & 7,09 \\
\hline Başkalarının haklarına saygı duymak & 10 \\
\hline Yapılan davranışın doğruluğunu-yanlı̧lı̆ını sorgulamak, muhakeme yapmak, kendini eleştirmek & 6,45 \\
\hline Fedakârlık yapmak & 8 \\
\hline Pişman olmak & 5,16 \\
\hline Dürüstlük, yalan söylememek & 3,22 \\
\hline Haksızlığa karşı isyan etmek & 22 \\
\hline Olaylardan ders çıarmak & 14,19 \\
\hline Başkalarının mutluluğuna sevinmek & 4 \\
\hline Affetmek, bağışlamak & 2,58 \\
\hline Şefkat & 1,29 \\
\hline Temiz-iyi kalpli & 1 & 0,64 \\
\hline Doğru davranışı takdir etmek & 2 & 1,29 \\
\hline Alçakgönüllü olmak & 4 & 2,58 \\
\hline Başkaları için faydalı olmak & 2 & 1,29 \\
\hline Paylaşmak & 2 & 1,29 \\
\hline & 3,87 \\
\hline
\end{tabular}

Tablo 3 incelendiğinde; araştırmaya dâhil edilen okul öncesi döneme ait 155 resimli hikâye ve masal kitabında vicdan gelişimini desteklediği düşünülen 23 farklı ifadeye rastlandığı görülmektedir. İncelenen kitapların 12 tanesinde $(\% 7,74)$ "yaptığından utanmak" ifadelerine; 21 tanesinde $(\%$ 13,54) "özür dilemek-af dilemek" ifadelerine; 35 tanesinde (\% 22,58) "zor durumda kalan kişilere yardım etmek" ifadelerine; 3 tanesinde $(\% 1,93)$ "haksızlık yapılması-haksızlığa uğramak" ifadelerine; 33 tanesinde (\% 21,29) "hatasinı anlamak" ifadelerine; 5 tanesinde (\% 3,22) "adil olmak" ifadelerine; 23 tanesinde (\% 14,83) "başkaları için üzülmek-başkalarına ac1mak-merhamet etmek" ifadelerine; 11 tanesinde $(\% 7,09)$ "başkalarının ya- 
şadıklarını anlamak-empati yapmak" ifadelerine; 10 tanesinde (\% 6,45) "başkalarının haklarına saygı duymak" ifadelerine; 8 tanesinde $(\% 5,16)$ "yapılan davranışın doğruluğunu-yanlışlığını sorgulamak-muhakeme yapmak-kendini yargilamak" ifadelerine; 5 tanesinde $(\%$ 3,22) "fedakarlık yapmak" ifadelerine; 22 tanesinde (\% 14,19) "pişman olmak" ifadelerine; 4 tanesinde (\% 2,58) "dürüstlük-yalan söylememek" ifadelerine; 2 tanesinde $(\%$ 1,29) "haksızlığa karşı isyan etmek" ifadelerine; 1 tanesinde $(\% 0,64)$ "olaylardan ders çıkarmak" ifadelerine; 2 tanesinde $(\%$ 1,29) "başkalarının mutluluğuna sevinmek" ifadelerine; 4 tanesinde (\% 2,58) "affetmekbağışlamak" ifadelerine; 2 tanesinde (\% 1,29) "şefkat" ifadelerine; 2 tanesinde (\% 1,29) "temiz kalpli" ifadelerine; 6 tanesinde (\% 3,87) "doğru davranış1 takdir etme" ifadelerine; 2 tanesinde $(\%$ 1,29) "alçakgönüllü olmak" ifadelerine; 2 tanesinde (\% 1,29) "başkaları için faydalı olmak" ifadelerine; 2 tanesinde $(\% 1,29)$ "paylaşmak" ifadelerine rastlanmıştır.

Vicdan gelişimini desteklediği düşünülen ifadeler arasında en çok "zor durumda olan- yardıma ihtiyacı olan kişilere yardım etmek" $(\%$ 22,58) ve "hatasını anlamak" (\% 21,29) ifadelerine; en az ise "olaylardan ders çıkarmak" $(\% 0,64)$ ifadelerine yer verildiği görülmektedir.

\section{Vicdan Gelişimini Desteklediği Düşünülen İfadelerin Yer Aldiğı Sayfa Sayı- sinin Toplam Sayfa Sayısina Oranı}

Sayfa sayılarına ve oranına tablo 4' de yer verilmiştir.

Tablo 4. Vicdan Gelişimini Desteklediği Düşünülen İfadelerin Sayfa Sayısına Göre Oranı

\begin{tabular}{lll}
\hline & F & \multicolumn{2}{c}{$\%$} \\
\hline Vicdan Gelişimini Desteklediği Düşünülen İfadelerin Yer Aldığı Toplam Sayfa Sayısı & 335 & 11,55 \\
\hline
\end{tabular}

Tablo 4 incelendiğinde; vicdan gelişimini desteklediği düşünülen ifadelerin yer aldığı sayfa sayısının 335, bunun tüm incelenen sayfa sayılarına oranının \%11, 55 olduğu görülmektedir.

\section{Hikaye ve Masal Kitaplarında Geçen Vicdan Gelişimini Desteklediği Düşünülen İfadelere Dair Alıntılar}

Aşağıda okul öncesi döneme ait resimli hikaye ve masal kitaplarında geçen ve vicdan gelişimini desteklediği düşünülen ifadelerin yer aldığ 1 cümlelerden alıntılara yer verilmiştir. 
Yaptı̆̆ından Utanmak: "Karınca kendini beğenmiş davranışlarından çok utanmış." (Andersen, 2015, 'Kibirli Karınca' kitabından s.14).

"Diğerleri de Bony'den özür dilediler. Onunla alay ettikleri için çok utanıyorlard.." (Çakta, 2014, ‘Tombul Fil Boni’ kitabından s. 16).

Özür Dilemek-Af Dilemek: "Afedersin, sana sormadan oyuncağını aldığım için özür dilerim. Yaptı̆̆ım doğru değil." (Sönmez, 2014, 'Köstebek Çıtırık' kitabından s.18).

"Derste seninle dalga geçtiğim için özür dilerim Todi. Çok yanlıs davrandım." (Şeyhi, 2014, 'Bıcırık Todi' kitabından s.22).

Zor Durumda Olan-Yardıma İhtiyacı Olan Kişilere Yardım Etmek: "Ama anne dişarısı çok tehlikeli dedi yavru kaplan. Dostluklar zor günler içindir dedi Sura. Baro'nun yardıma ihtiyacı var." (Çakta, 2014, 'Yaşlı Kaplan Sura' kitabindan s. 11).

"Hemen arkadaşlarmı kurtarmak için çalışmaya başladılar. Evsiz kalan tavuk ve kazlara komşuları sahip çıktılar. Bu zamana kadar hiç yardım etmediği hayvan arkadaşları onu bile yalnı bırakmamışlardı. Tembel Tavuk gerçekten çok etkilenmişti." (Bozcan, 2011, 'Yardımsever Tavuk' kitabından s. 8-12-13).

"Sarı sincap, komşuluklarm böyle günler için varolduğunu söyleyerek Mavi Sincap'a ambarmdan yeteri kadar yiyecek vermiş. Aynca yiyecekleri borç olarak vermediğini, ihtiyaçları olduğunda çekinmeden tekrar gelebileceğini söylemiş. Mavi Sincap komşularmın davranışlarmdan çok etkilenmiş." (Tayfur, 2009, 'Sincap Ailesi' kitabından s.15).

Haksızlık Yapmak, Haksızlı̆̆a Uğramak: "Nazik Hanım: Haksızh̆̆a uğradığımız durumlarda bile kendimizi kaybetmemeliyiz. Öfkene kapılmadı̆̆ın için seni kutlarım yavrum." (Sönmez, 2014, 'Köstebek Çıtırık' kitabından s.22).

Hatasını Anlamak: "Birden kendi yaptıkları aklına gelmiş. Aynı saygısızlı̆̆ı daha önce defalarca kendisi yapmıştı. Hatasını anlamış ve çok utanmış." (Tanışır, 2017, 'Kurbağa Vurak' kitabından s.14).

“Şavşav, Pumpum'u izliyor, kendi hataların anlıyormuş. Haklymmıssın. Ben gerçekten kötü bir şoförmüşüm. Otobüsüme çok kötü davranmışım. Bundan sonra 
daha sakin ve dikkatli olacağım." (Gasemnia, 2014, 'Otobüs Tostos' kitabından s. 28).

Adil Olmak: "Tarla faresi çok adaletli bir hakimdi. Kimsenin hakkın kimseye geçirmezdi. Yüce mahkememiz, davacı Tavşan Bey'i haklı bulmuştur dedi. Yapılan iyi bir şey olsa bile sahibinden izin alınmadan yapılmıştı. Meğer iyilik yapmak, adaletle yaşamak ve başkaları tarafindan sevilmek ne güzeldi." (Bozcan, 2011, 'Hakimin Adaleti' s.12-13).

Başkaları İçin Üzülmek, Acımak, Merhamet: "Tarla faresi; "çok uzun zamandir hiçbir şey yemedim."dedi. Minik zebra tarla faresi için çok üzüldü." (Çakta, 2014, 'Minik Zebra ile Tarla Faresi' kitabından s.10).

Başkalarının Yaşadıkların Anlamak, Empati: “Ama kimse Topiş'le oynamak istemedi. Nasıl üzüldüğünü görmeliydin baba. Kendimi onun yerine koyunca çok üzüldüm. Babası Şıpşıp' a dikkatle dinledi. Sonra şunları söyledi: Aferin yavrum. Topiş'in neler hissettiğini anlamaya çalışmışsı. Bence bu konuyu arkadaşlarınla da konuşmalısın. Şıpşıp arkadaşlarma: Dün Topiş'e çok kötü davrandik. Onu oyuna almayınca kendini çok yalnız hissetmiş olmalı. Onun yerinde siz olsaydınız ne hissederdiniz diye sordu." (Sönmez, 2014, 'Japon Balığı Şıpşıp' kitabından s.1920-21).

Başkalarının Haklarına Saygı Duymak: "Topaç senin olabilir ama onların haklarnna sayg göstermeliydin. Bence onlardan özür dilersen yeniden birlikte oynayabilirsiniz." (Çakta, 2014, 'Moli'nin Topacı' kitabından s.15).

\section{Yapılan Davranışın Doğruluğunu-Yanlışlğ̆ın Sorgulamak, Muhakeme} Yapmak, Kendini Eleştirmek: "Timbo'nun kızginlığı yavaş yavaş geçiyordu. Yaptığı davranıştan rahatsı olmaya başlamıştı. Acaba arkadaşına haksızlık mı etmişti? Şimdi pişmandr. Ama özür dilemek zoruna gidiyordu. "Özür dilerim, seni kıskandığım için kötü davrandım" demek kolay değildi. Timbo, Zimbo' nun iyi davranışlarm düşünüyordu: "Yiyeceklerini hep benimle paylaşır, boya kalemlerini kullanmama izin verir. Ninemin hastalı̆̆na bile üzülmüştü." Olanlar düşündükçe Timbo'nun pişmanlığı arttı." (Sönmez, 2014, 'Timbo ile Zimbo' kitabından s. 14-15).

Fedakarlık Yapmak: "Vatanımızı düşmanlardan kurtarmak için her türlü fedakarlığı yaptık." (Çakta, 2014, 'Geçit Töreni' s. 11). 
Pişman Olmak: "Yalan söylerken keyif aldığın düşündü. Şimdiyse sadece pişmandr. Bütün hayvanlardan kendisini affetmelerini istedi." (Kasımi, 2010, 'Yalan Söyleyen Kurbağa' kitabından s.10).

Dürüstlük, Yalan Söylememek: "Hayvanlarn birbirlerine karşı dürüst davranmalarma, kimsenin kimseye yalan söylememesine çok önem verirdi." (Bozcan, 2011, 'Kral Cimbo' kitabından s. 1).

Haksızlı̆̆a Karşı İsyan Etmek: "Bu duruma önce kuşlar isyan etmiş." (Tayfur, 2009, 'Aslanın Krallı̆̆g' kitabından s.6).

Olaylardan Ders Çıkarmak: "Bu olay sayesinde Timbo şunları öğrendi: Kıskançlik rahatsız edici bir duyguydu ve yanlış davranışlara neden olabiliyordu. Ayrıca özür dilemesi gereken durumlarda acele etmeliydi." (Sönmez, 2014, "Timbo ile Zimbo' kitabından s.31).

Başkalarmın Mutluluğuna Sevinmek: "Küçük Kurbi' nin annesine kavuştuğunu gören tüm hayvanlar çok sevinmiş." (Şeyhi, 2014, 'Küçük Kurbi' kitabından s.31).

Affetmek, Bağışlamak: "Tabiki affederim Meluş, diye cevap vermiş." (Şeyhi, 2014, 'Cup Cup/Muşmuş'un Kuyruğu' kitabından s.195).

"Gerçeği söylediğin için seni affediyorum Tintin." (Sönmez, 2014, 'Tintin ile Posti' kitabından s. 26).

Şefkat: "Kirpi Topik şefkatli bir kirpiymiş. Çatçat'a kırgin olsa da yardım etmek istemiş. (Gasemnia, 2014, 'Acı Biber Çatçat' kitabından s. 26).

Temiz- Iyi Kalpli: "Evladım, sen çok temiz kalpli ve dürüst bir insanmışsın." (MEB, 2020, 'Altın Balta' kitabından s. 10).

Doğru Davranışı Takdir Etmek: "Annesi doğru davrandiğı için onu tebrik etmiş." Çiçekleri koparsaydın üzülürdüm yavrucuğum" demiş." (Gasemnia, 2014, 'Kanguru Hopidik' kitabından s. 26). 
"Aferin sana Fati, bana doğruyu söylemen beni çok mutlu etti." (Çakta, 2014, 'Sincap Kardeşler' kitabından s.14).

Alçak Gönüllï Olmak: "Serçe Hanım: "Ama böyle böbürlenmen hoş değil. Kendini başkalarmdan üstün görüp övünmek yerine alçak gönüllü olmalısın." diye ona nasihatte bulunmuş." (Şeyhi, 2014 'Cup Cup / Hoş Geldin Kardan Adam' kitabindan s. 362).

Başkaları İçin Faydalı Olmak: "Ama sen bir çivisin. Senin görevin bu! Görevini yerine getirerek başkalarma faydal olman gerekiyor. Çiçi, görevlerini yerine getirip faydah olmanın önemini anlamış." (Şeyhi, 2014, 'Paslı Çivi Çiçi' kitabından s. $235,243)$.

Paylaşmak: "Ama bu olay sayesinde paylaşmanın önemini anlamışlar." (Şeyhi, 2014, ‘Cup Cup/ Yünlü ile Kahve' kitabından sayfa 324).

\section{Tartışma ve Sonuç}

Çocuğun geleceğine yön vermesi, çocukta olumlu benlik algısı gelişmesi, çocukta pek çok ahlaki değer, yargı ve inançların oluştuğu, ailenin aktif olarak yer aldığı dönem olması bakımından okul öncesi eğitim süreci oldukça önemli bir dönemdir (Oktay ve Polat Unutkan, 2005).

Vicdan gelişimi; ahlak gelişiminin önemli bir parçasıdır. Çünkü kişinin ahlaklı olabilmesi kuvvetli bir vicdan barındırmasına bağlı görülmektedir (Yavuz, 1994). Resimli masal ve hikaye kitapları çocuk gelişiminde olduğu kadar ahlak eğitiminde de ebeveyn ve eğitimciler için en büyük yardımc1lardandır. Çocuklar kitaplar sayesinde olumlu rolleri görüp model alarak bu rolleri kendi hayatlarına taşırlar (Mardi, 2006). Bu sebeple bu araştırmada okul öncesi döneme hitap eden resimli hikaye ve masal kitapları vicdan gelişimini destekleyen ifadeler bakımından incelenmiştir.

Araştırma kapsamında okul öncesi döneme ait 155 tane resimli masal ve hikaye kitabı incelenmiştir. Bu kitapların 91 tanesinde vicdan gelişimini desteklediği düşünülen ifadelere rastlanmış; 64 tanesinde bu ifadelere rastlanmamıştır. Vicdan gelişimini desteklediği düşünülen ifadelerin çeşitliliği geniş tutulduğundan bu oranın düşük olduğu söylenebilir. 
Araştırma kapsamında incelenen toplam sayfa sayısı 2900'dür. Vicdan gelişimini desteklediği düşünülen 23 farklı ifadenin yer aldığı toplam sayfa sayısı ise 335 olarak belirlenmiştir. Bu oran \%11,55'e denk gelmektedir. İncelenen kitapların pek çoğunun sayfa sayısının yarısında metin olmayıp yalnızca resim olduğu düşünüldüğünde bu oran daha yüksek çıksa da yine de ortalama bir seviyededir. Dirican ve Dağlığlu (2014), Resimli Hikaye Kitaplarının Bazı Temel Değerler Açısından İncelenmesi çalışmasında kitaplardaki değer ifade eden cümlelerin toplam cümleye $\% 28$ oranı ile yüksek bulduklarını ifade etmişlerdir.

Araştırma sırasında kitaplarda vicdan gelişimini desteklediği düşünülen 23 farklı ifade kaydedilmiştir. Bu ifadeler: "yaptı̆̆ından utanmak", "özür dilemek-af dilemek", "zor durumda kalan kişilere yardım etmek", "haksızlık yapılması-haksızlığa uğramak", "hatasını anlamak", "adil olmak”, "başkaları için üzülmek-başkalarına acımak-merhamet etmek", "başkalarının yaşadıklarını anlamak-empati yapmak", "başkalarının haklarına saygı duymak", "yapılan davranışın doğruluğunu-yanlışlığını sorgulamakmuhakeme yapmak-kendini yargılamak", "fedakarlık yapmak", "pişman olmak", "dürüstlük-yalan söylememek", "haksızlığa karşı isyan etmek", "olaylardan ders çıarmak", "başkalarının mutluluğuna sevinmek", "affetmek-bağışlamak", "şefkat", "temiz kalpli" , "doğru davranışı takdir etmek", "alçakgönüllü olmak", "başkaları için faydalı olmak", "paylaşmak" ifadeleridir. Bu ifadeler rastlandıkları kitaplarda farklı oranlarda yer almaktadır. Kitaplarda vicdan gelişimini desteklediği düşünülen ifadelerden en çok rastlanan üç ifade sırasıyla; "zor durumda olan-yardıma ihtiyacı olan kişilere yardım etmek", "hatasını anlamak" ve "başkaları için üzülmek, acımak, merhamet" tir. En az rastlanan ifade ise; "olaylardan ders çıkarmak" tır.

Kıral (2016);' nın sınıf öğretmenleriyle yaptığı araştırmanın sonuçları bu çalışmadan elde edilen verilerle aynı doğrultudadır. Öğretmenler "vicdanlı çocuk" özelliklerini sıralarken ortaya koydukları ifadeler bu araştırmada bulgulanan 23 ifadeyi de içerisinde barındırmaktadır. Öğretmenlerin verdikleri cevaplar arasında "vicdanlı çocuk" en çok yaptıklarından pişmanlık duyan ve yardımsever olarak belirtilmiştir. Kılıç (2009); Türk ve Batı klasiklerinde "adalet" unsuruna sık rastlanıldığını fakat okul öncesi dönem kitaplarında ise "adalet" unsuruna oldukça az yer verildiğini ifade etmiştir. Bu araştırmada da incelenen kitapların yalnızca 5 tanesinde "adalet" ifadesine rastlanmıştır. Karatay (2011); MEB' in tavsiye ettiği 100 Temel Eser üzerine 
yaptığı araştırmada "dürüstlük" öğesine oldukça az yer verildiğini ortaya koymuştur. Bu bulgu araştırmamızın verileriyle orantılıdır. "Dürüstlük" ifadesi kaydedilen 23 ifade arasından rastlanma oranına göre 15. sirada yer almaktadır. Court ve Rosental (2007), İsrail'deki anaokulları kitaplı̆̆ında bulunan çocuk kitapları üzerinde yaptıkları araştırmada kitaplarda en çok "karşılıklı saygı" ifadelerine yer verildiğini belirtmişlerdir. Oysa araştırmamızdaki kitapların tamamı da anaokulları kitaplığından alınmış olsa da "başkalarının haklarına saygı duyma" ifadelerine yalnızca 10 farklı kitapta rastlanmıştır. Bunun istenen düzeyde olmadığı söylenebilir.

Sonuç olarak okul öncesi dönem çocukları için masal ve hikaye kitaplarının eğitici yönü düşünüldüğünde vicdan gelişimini desteklediği düşünülen ifadelerin çocuk kitaplarında yer alma oranı ve bu ifadelerin bulundukları sayfa sayıları oranının yeterli düzeyde olmadığı düşünülmektedir. Nitekim araştırmaya dahil edilen bu kitapların karakter ve değerler ile ilgili olduğu düşünüldüğünde bu oranın az olduğu görülmektedir. Bu oranların yükseltilmeye çalışılması çocukta vicdan gelişiminin temellerinin daha güçlü bir şekilde atılmasına katkı sunacaktır.

Bu bilgiler doğrultusunda öneriler şöyle sıralanabilir:

- Yazarlar ve yayınevleri çocuklarda vicdan gelişimini desteklemeyi amaçlayan çocuk kitapları hazırlayabilirler.

- Alan uzmanları okul öncesi dönem vicdan gelişimi konusunda çalışmalar yaparak yazarlarla paylaşabilirler. 


\title{
EXTENDED ABSTRACT
}

\section{Examination of Expressions Regarding Development of Conscience in Illustrated Story and Tale Books}

\author{
Fatma Balık - Munise Duran \\ İnönü University
}

The child adopts the belief, values and morals of the society which he lives in and maintains his entire life in accordance with these. This situation reminds us the necessity of an education program in line with value judgments of the society as from the first years of the child's life. One of the most-discussed issues of these education programs is how to raise a good person. Thus, this question is within the field of morals and morals becomes an important subject of education (Oruç, 2010).

Conscience education is in the centre of moral education since the fact that the child is well-behaved depends on his having a strong conscience (Yavuz, 1994). Conscience is an emotion that makes the person happy when he does good things and makes him unhappy when he does bad things. It leads the individual to what is right and keeps him away from the wrongs; however, he cannot find the truth only through his conscience. Conscience should certainly be trained and directed positively (Kahveci, 2012).

Even if the works created for children are primarily literary works, they also serve to moral education. Though these works are not written directly to train the child, they aim at having good impressions and influences on the child. They encourage the children for struggle to be virtuous, help them make right decisions, supports the children to develop a value system and enables them to have positive attitudes and behaviours in case of events and situations they may encounter(Bohlin, 2005; Gibbs and Earley, 1994; Karatay, 2007).

When the studies about the pre-school story books are analysed, it is seen that the number of the studies dealing with conscience development is very few. Such a study has been needed to draw attention to the fact that conscience development, which is an important part of moral development, is a subject to be considered in pre-school period. It is thought that the study 
will contribute to researchers who want to study in this field, authors, educationists, parents and preschool children. Accordingly, it was aimed in this study to examine preschool illustrated story and tale books published between 2009 and 2020 in terms of the elements supporting conscience development. While dealing with these elements, formative, directive, preventive and interrogative effects of conscience on behaviour were taken into consideration.

This study is in content analysis model that is one of the qualitative research methods. The population of the study includes illustrated tale and story books appealing preschool period. The sample is composed of 155 books on the covers of which character or values education is written and that were determined with purposeful sampling method among preschool illustratedstory and tale books published between 2009 and 2020. The books in the sample were provided from kindergarten libraries in Diyarbakır city centre.

3-item analysis form was prepared by the researchers for this study. The form has sections about whether there are expressions supporting conscience development in books; if there are any, how many pages of the books include them; what these expressionsare and the sentences emphasizing these expressions. All the books used in this study were read one by one and carefully by the researchers, information was written in the relevant places in the analysis form and required coding was made. To ensure the internal consistency (reliability) in coding, the data were independently coded twice by the researchers at two different times. Second coding was made two weeks later than the first one. In addition, coding was read by three preschool teachers from different schools and they were requested to make coding in line with themes and subthemes created. Afterwards, coding was compared and reliability was calculated by using Miles and $\mathrm{Hu}-$ berman's formula (Reliability = consensus / consensus + disagreement $\mathrm{X}$ 100) (1994).The consistency between these coding within the context of reliability particular to this study was calculated as $100 \%$.

It was seen that among 155 preschool illustrated story and tale books included in the study, expressionssupporting conscience development were found in 91 books (58,71\%) and 64 of these books (41,29\%) did not include expressionsregarding conscience development. 23 different expressionsconsidered to support conscience development in 155 preschool illustrated sto- 
ry and tale books included in the study were recorded. The expressionsof "being embarrassed", "apologizing", "helping people who are in a difficult situation", "to be subjected to injustice", "understanding his own mistakes", "being fair", "feeling sorry for others -pity others-to show mercy", "understanding what others go through -empathy", "respect for others' rights", "questioning whether the behaviour is right or wrong-judgement-selfjudgment ", "to sacrifice", "to regret", "honesty-not tell lies", "to rebel against injustice" , "learning from the events", "be pleased for others' happiness", "to forgive", "affection", "ingenuous", "appreciate the right behaviour", "to be unpretentious", "to be helpful for others" and "to share" were found

in

12(7,74\%),21(13,54\%),35(22,58\%),3(1,93\%),33(21,29\%),5(3,22\%),23(14,83\%), 11 (7,09\%),10(6,45\%),8(5,16\%),5(3,22\%),22(14,19\%),4(2,58\%),2(1,29\%),1(0,64\%),2 $(1,29 \%), 4(2,58 \%), 2(1,29 \%), 2(1,29 \%), 6(3,87 \%), 2(1,29 \%), 2(1,29 \%) \quad$ and $\quad 2($ $1,29 \%)$ of the books, respectively.

It was seen that among the expressionsthat are considered to support conscience development, "helping people who are in a difficult situation" $(\%$ 22,58) and "understanding his own mistakes" $(\%$ 21,29) were the most common expressionsand "learning from the events" $(\% 0,64)$ is the one that is the least included. It was found that the number of pages including expressionsabout conscience development was 335 and the ratio of this number to the whole analysed pages was $11,55 \%$. When it is regarded that there are not texts but only illustrations on the half of the pages of most of the books analysed, even if this rate is higher, it is still at an average level. DiricanandDağlıoğlu (2014) indicated in their study called Analysing Some Basic Values in Illustrated Story Books that they found the ratio (28\%) of the sentences expressing a value to all the sentences in the books was high.

Consequently, when the educational aspect of tale and story books for preschool children are considered, it is thought that the ratio ofexpressionssupporting conscience development in children's books and the number of pages on which these expressionsare available are not sufficient. As a matter of fact, when it is considered that these books included in the study are about character and values, this ratio becomes low. Trying to increase these rates will contribute to ensuring a stronger foundation of conscience development in the child. 


\section{Kaynakça / References}

Aksan, N. ve Kochanska, G. (2005). Conscience in childhood: old questions, new answers. Developmental Psychology, 41(3), 506.

Ary, D., Jacobs, L., Razevieh, A., and Sorensen, C. (2006). Introduction to research in education. Belmont, CA: Wadsworth.Brooks J.G. \& Brooks, M.G. In Search of understanding: The case for Constructivist Classrooms. Association for Supervision and Curriculum Development. Associtation for Supervisionand Curriculum Development Alexandria, Virginia. http://www.ascd.org.

Baltacı, A. (2019). Nitel araştırma süreci: Nitel bir araştırma nasıl yapılır?. Ahi Evran Üniversitesi Sosyal Bilimler Enstitüsü Dergisi, 5(2), 368-388.

Berk, E. L. (2013b). Çocuk gelişimi. (Çev. A. Dönmez). Ankara: İmge.

Bohlin, K. E. (2005). Teaching character education thorough literature. USA: Routledge.

Büyüköztürk, Ş., Çakmak, E. K., Akgün, Ö. A., Karadeniz, Ş. ve Demirel, F. (2016). Bilimsel Araştırma Yöntemleri. Ankara: Pegem Akademi.

Court, D. ve Rosental, E. (2007). Values embodied in children's literature used in early childhood education in Israeli state schools. Early Childhood Education Journal, 34(6), 407-414.

Dirican, R , Dağlığlu, H . (2014). 3-6 Yaş Grubu Çocuklarına Yönelik Yayımlanan Resimli Hikaye Kitaplarının Bazı Temel Değerler Açısından İncelenmesi . Cumhuriyet Uluslararası Eğitim Dergisi , 3 (2) , 44-69 . DOI: 10.30703/cije.321341

Dodson, F. (1999). Çocuk Eğitimi El Kitabı. (Çev. A. Durmaz). İstanbul: Ravza Yayınları.

Frankel, J., and Wallen, N. (2000). How to design and evaluate research in education. Boston, MA: McGraw-Hill Higher Education.

Gibbs, L. J. ve Earley, E. J. (1994). Using children's literatüre to develop core values. Bloomington: Phi Delta Kappa Educational Foundation.

Göllner, R., Damian, R. I., Rose, N., Spengler, M., Trautwein, U., Nagengast, B., ve Roberts, B. W. (2017). Is doing your homework associated with becoming more conscientious? Journal of Research in Personality, 71, 1-12.

Grinder, E.R. (1964). Relations between Behavioral and Cognitive Dimensions of Conscience in Middle Childhood. Child Development, 35(3), 881-891.

Guba, E. G. ve Lincoln, Y. S. (1994). Competing paradigms in qualitative research. Handbook of qualitative research, 2(105), 163-194.

Kahveci, A. (2012). J.J. Rousseau'da Ahlâkî Vicdan ve Değeri. Çukurova Üniversitesi İlahiyat Fakültesi Dergisi, 12(1), 205-213. 
Karatay, H. (2007). Değer Aktarımı Açısından Yerli ve Yabancı Çocuk Edebiyatı Ürünleri. 38. ICANAS, Uluslararası Asya ve Kuzey Afrika Çalısmaları Kongresi'nde Sunulmuştur. Ankara.

Karatay, H. (2011). Transfer of values in the Turkish and Western children's literary works: character education in Turkey. Educational Research and Reviews, 6(6), $472-480$.

Kılıç, A. İ. (2009). Yüz Temel Eserde Dini ve Ahlaki Değerler. Yüksek Lisans Tezi, Ondokuz Mayıs Üniversitesi, Sosyal Bilimler Enstitüsü, Samsun.

Kıral, B.(2016). Sosyal Bilgiler ve Hayat Bilgisi Programında Yer Alması Gereken Bir Değer: Vicdan ve Vicdanlı Öğrenciler. USBES V, 2016 Bildiriler Kitabı, 185195.

Klenke, K. (2016). Qualitative research in the study of leadership. Emerald Group Publishing Limited.

Kochanska, G., ve Murray, K. T. (2000). Mother-child mutually responsive orientation and conscience development: From toddler to early schol age. Child development, 71(2), 417-431.

Mardi, H. Ö. (2006). Çocuk kitapları resimlemede karakter yaratma. Yüksek Lisans Tezi, Dokuz Eylül Üniversitesi, Eğitim Bilimleri Enstitüsü, İzmir.

Marjanovic, Z., Struthers, C. W., Cribbie, R., ve Greenglass, E. R. (2014). The Conscientious Responders Scale: A new tool for discriminating between conscientious and random responders. Sage Open, 4(3), 2158244014545964.

Milli Eğitim Bakanlığı (2013). Çocuk gelişimi ve eğitimi-ahlak gelişimi. Ankara: Milli Eğitim Bakanlığı Yayınları.

Miles, M, B., ve Huberman, A. M. (1994). Qualitative data analysis: An expanded Sourcebook. (2. ed). Thousand Oaks, CA: Sage.

Oktay, A. ve Polat Unutkan, Ö. (2005). Okul öncesi eğitimde güncel konular. İstanbul: Morpa Yayınları.

Oruç, C. (2010). Okul öncesi dönem çocuğunda ahlaki değerler eğitimi. Eğitim ve Insani Bilimler Dergisi, 1(2), 37-60.

Özeri, Z. N. (2004). Okul öncesi din ve ahlak eğitimi. (1. Basım). İstanbul: Dem Yayınevi. Özgün, Ö. (2012). Ahlak gelişimi. E. Deniz (Ed.). Erken Çocukluk Döneminde Gelişim, (4.baskı) içinde (s. 267-285). Ankara: Maya Akademi.

Patton, M. (2002). Qualitative research and evaluation methods. Thousand Oaks, CA: Sage Publications.

Rousseau, J.J.(2002). Emile. (Çev: M. Baştürk, Y. Kızılçim). Erzurum: Babil Yayınları. Seale, C. (1999). Quality in qualitative research. Qualitative Inquiry, 5(4), 465-478. 
Torun, N.Y., Özşahin, A. ve Sütçügil, L. (2009). Dikkat eksikliği hiperaktivite bozukluğunun yetişkinlikteki yansımaları. Klinik Psikiyatri, 12, 43-50. http://www.klinikpsikiyatri.org/.

Tuzcuoğlu, S. (2014). Kişilik gelişimi. B. Aydın. (Ed.). Eğitim Psikolojisi (gelişim ve öğrenme) (3. baskı) içinde (s. 123-155). Ankara: Nobel Akademik Yayınclik.

Yavuz, K. (1994). 99 soruda çocuk ve din. İstanbul: Çocuk Vakfı Yayınları.

\section{Kaynakça Bilgisi / Citation Information}

Balık, F. ve Duran, M.(2021).Resimli hikaye ve masal kitaplarında geçen vicdan gelişimine yönelik ifadelerin incelenmesi. OPUSUluslararası Toplum Araştırmaları Dergisi, 17(37), 4049-4071.DOI: 10.26466/opus. 865378 